\title{
A decade of increases in Medicare Part B pharmaceutical spending: what are the drivers?
}

\author{
Alvaro San-Juan-Rodriguez, PharmD, MS; Walid F Gellad, MD, MPH; William H Shrank, MD, MSHS; \\ Chester B Good, MD, MPH; and Inmaculada Hernandez, PharmD, PhD
}

\section{What is already known about this subject}

- Medicare Part B pharmaceutical spending more than doubled in 20062017, increasing from $\$ 13.9$ billion to $\$ 32.0$ billion.

- Previous reports have described which individual drugs, drug classes, and disease categories comprise the largest share of Medicare Part B pharmaceutical spending.

- It remains unclear whether increased spending over time represents increased utilization or increased cost per claim.

\section{ABSTRACT}

\section{BACKGROUND: Medicare Part B}

pharmaceutical spending has increased rapidly, more than doubling in 2006-2017. Yet, it is unclear whether this increase was driven by increased utilization or increased cost per claim.

OBJECTIVE: To evaluate the relative impact of changes in drug utilization and cost per claim on changes in Medicare Part B pharmaceutical spending in 2008-2016 overall, by drug type (specialty and nonspecialty) and therapeutic category.

\section{What this study adds}

- In 2008-2016, pharmaceutical spending in Medicare Part B increased by $34 \%$, driven by a $53 \%$ increase in the cost per claim; meanwhile, utilization decreased by $12 \%$.

- Medicare Part B pharmaceutical spending grew considerably in recent years, despite decreased utilization, which was driven by increases in the cost per claim and was a product of rising drug prices and increased utilization of more expensive specialty drugs.

\section{Author affiliations}

Alvaro San-Juan-Rodriguez, PharmD, MS, and Inmaculada Hernandez, PharmD, PhD, Department of Pharmacy and Therapeutics, School of Pharmacy, University of Pittsburgh, Pittsburgh, PA. Walid F Gellad, MD, MPH, Division of General Internal Medicine, School of Medicine, University of Pittsburgh, Pittsburgh, PA; William H Shrank, MD, MSHS, Humana, Louisville, KY; and Chester B Good, MD, MPH, Insurance Services Division, UPMC Health Plan, Pittsburgh, PA.

AUTHOR CORRESPONDENCE:

Alvaro San-Juan-Rodriguez,

412.378.2940; als440@pitt.edu

J Manag Care Spec Pharm. 2021;27(5):565-73

Copyright (C)2021, Academy of Managed Care Pharmacy. All rights reserved.

RESULTS: Pharmaceutical spending in Medicare Part B increased by $34 \%$ from 2008-2016, driven by a $53 \%$ increase in the cost per claim. Utilization decreased by $12 \%$. Spending on specialty drugs increased by $56 \%$, driven by a $48 \%$ increase in the cost per claim and a $6 \%$ utilization increase. Spending on nonspecialty drugs decreased by $32 \%$ driven by an $18 \%$ reduction in the cost per claim and a $17 \%$ reduction in utilization. Spending on ophthalmic preparations increased by $281 \%$, driven by a $238 \%$ utilization increase and a $13 \%$ increase in the cost per claim. Spending on antiarthritic and immunologic agents increased by $159 \%$, driven by a $117 \%$ increase in the cost per claim and a $19 \%$ utilization increase. 
CONCLUSIONS: Medicare Part B pharmaceutical spending grew in recent years, despite decreased utilization, driven by an overall increase in the cost per claim. This was a product of rising drug prices and increased utilization of more expensive specialty drugs. These findings support the development of policies that aim to spur competition and control price growth of provider-administered drugs.

Over the last decade, spending on drugs administered by providers in physician offices, clinics, or hospital outpatient departments has increased substantially, accounting for an increasing proportion of pharmaceutical spending. ${ }^{1}$ In Medicare, provider-administered drugs are covered under Part B. ${ }^{2}$ Pharmaceutical spending in Part B more than doubled between 2006 and 2017, from $\$ 13.9$ billion to $\$ 32.0$ billion, accounting for $17 \%$ of total Medicare drug spending in 2017.3.,4

Previous reports have described which individual drugs, drug classes, and disease categories comprise the largest share of Medicare Part B pharmaceutical spending., ${ }^{1,-6}$ However, it is still unclear whether increased spending over time represents increased utilization or increased cost per claim. Clarifying the factors behind increases in Medicare Part B pharmaceutical spending is important because spending on provider-administered drugs is projected to continue growing at even faster rates as new provider-administered biologics gain approval by the US Food and Drug Administration (FDA). ${ }^{1}$ Furthermore, for Medicare beneficiaries without any supplemental coverage, out-of-pocket spending on Part B drugs has no catastrophic threshold, adding a significant financial burden. Understanding drivers of increasing Part B spending is of major relevance for informing policymakers of the development of measures aiming to contain its growth.

The objective of this study was to assess the relative contribution of changes in drug utilization and cost per claim to changes in Medicare Part B pharmaceutical spending in 2008-2016.

\section{Methods}

\section{DATA SOURCES AND STUDY SAMPLE}

We obtained 2008-2016 claims data from a 5\% random sample of fee-for-service Medicare beneficiaries from the Centers for Medicare \& Medicaid Services (CMS). Services covered under Medicare Part B are billed using Healthcare Common Procedure Coding System (HCPCS) codes. In order to differentiate Medicare Part B drug claims from the rest of claims, we obtained 2008-2016 quarterly lists of HCPCS codes for Part B-covered drugs from CMS. ${ }^{7}$ Each year, we extracted all Medicare claims of separately payable "J" codes (drug codes) and "Q" codes (temporary codes). This included injectable and infusion drugs, typically administered by providers; certain self-administered drugs, such as oral anticancer agents, oral antiemetics, immunosuppressive drugs, or hemophilia clotting factor; and drugs used in conjunction with durable medical equipment, such as inhalation drugs used with a nebulizer. Our initial sample included 663 HCPCS codes. We excluded all claims with denied payments. After these exclusions, our sample included 597 HCPCS codes.

We identified all National Drug Code (NDC) numbers for the study sample using CMS crosswalks of HCPCS codes to NDC numbers. Then, we used a list obtained from a national pharmacy benefit manager to identify NDC numbers of specialty medications, ${ }^{8}$ as previously done in the literature. ${ }^{9}$ HCPCS codes were classified as specialty when at least $50 \%$ of their corresponding NDC numbers were identified as specialty medications. All other HCPCS codes were classified as nonspecialty (Table 1). We used the Uniform System of Classification codes obtained from AnalySource (reprinted with permission by First Databank, Inc) to identify therapeutic classes. ${ }^{10,11}$ Specifically, we classified HCPCS codes into a convenience sample of 7 therapeutic classes with the largest cumulative spending in 2008-2016, including antineoplastic agents, antiarthritic and immunologic agents, blood factor and hemostatic modifiers, gastrointestinal agents, hospital solutions, musculoskeletal agents, and ophthalmic preparations. HCPCS codes that did not fall under either of these 7 therapeutic classes were classified as "other classes" (Table 1).

Given the widespread off-label use of bevacizumab for ophthalmic indications, we differentiated its intravitreal use from all other uses. Intravitreal use of bevacizumab was defined as having the HCPCS code J9035 (bevacizumab injection) and the Current Procedural Terminology code 67028 (under vitreous procedures on the posterior segment of the eye) concomitantly billed under the same claim. ${ }^{12}$

\section{OUTCOMES}

Outcomes included spending, utilization, and cost per claim. Spending was defined as the sum of total payments (Medicare program payments and beneficiary cost sharing) for all claims for drugs in the study sample. We defined utilization as the total number of claims (more details about our selection of number of claims as measure of utilization 

Drug Type, and by Therapeutic Class, 2008-2016

\begin{tabular}{|c|c|c|c|c|c|c|c|c|c|c|c|}
\hline & \multicolumn{3}{|c|}{$\begin{array}{l}\text { Spending per } \\
\text { beneficiary- year }\end{array}$} & \multicolumn{3}{|c|}{$\begin{array}{l}\text { Number of claims per } \\
\text { beneficiary-year }\end{array}$} & \multicolumn{3}{|c|}{ Cost per claim } & \multirow{2}{*}{$\begin{array}{c}\text { Contribution } \\
\text { toward } \\
2008-2016 \\
\text { overall }\end{array}$} & \multirow{2}{*}{$\begin{array}{c}\begin{array}{c}\text { Contribution } \\
\text { toward }\end{array} \\
\begin{array}{c}2008-2016 \\
\text { overall }\end{array} \\
\begin{array}{c}\text { Utilization } \\
\text { decrease }\end{array}\end{array}$} \\
\hline & 2008 & 2016 & Change & 2008 & 2016 & Change & 2008 & 2016 & Change & & \\
\hline Overall $(\mathrm{N}=597)$ & 213.2 & 286.6 & $34.4 \%$ & 0.7848 & 0.6886 & $-12.3 \%$ & 271.7 & 416.3 & $53.2 \%$ & $100.0 \%$ & $100.0 \%$ \\
\hline \multicolumn{12}{|l|}{ Drug type } \\
\hline $\begin{array}{l}\text { Specialty drugs } \\
(n=159)\end{array}$ & 160.9 & 251.1 & $56.1 \%$ & 0.1598 & 0.1689 & $5.7 \%$ & $1,006.9$ & $1,486.5$ & $47.6 \%$ & $113.7 \%$ & $-71.1 \%$ \\
\hline $\begin{array}{l}\text { Nonspecialty drugs } \\
(n=438)\end{array}$ & 52.4 & 35.5 & $-32.1 \%$ & 0.6250 & 0.5197 & $-16.9 \%$ & 83.8 & 68.4 & $-18.4 \%$ & $-13.7 \%$ & $171.1 \%$ \\
\hline \multicolumn{12}{|l|}{ Therapeutic class } \\
\hline $\begin{array}{l}\text { Ophthalmic } \\
\text { preparations }^{\mathrm{a}}(\mathrm{n}=13)\end{array}$ & 18.0 & 68.6 & $280.9 \%$ & 0.0145 & 0.0491 & $238.3 \%$ & $1,242.0$ & $1,398.2$ & $12.6 \%$ & $57.3 \%$ & $-113.8 \%$ \\
\hline $\begin{array}{l}\text { Antiarthritic and } \\
\text { immunologic agents }{ }^{b} \\
(n=35)\end{array}$ & 10.1 & 26.1 & $159.0 \%$ & 0.0337 & 0.0403 & $19.4 \%$ & 298.3 & 647.0 & $116.9 \%$ & $18.5 \%$ & $-29.7 \%$ \\
\hline $\begin{array}{l}\text { Hospital solutions }{ }^{c} \\
(n=43)\end{array}$ & 4.1 & 8.8 & $117.0 \%$ & 0.0647 & 0.0294 & $-54.5 \%$ & 62.7 & 299.1 & $377.1 \%$ & $5.6 \%$ & $95.2 \%$ \\
\hline $\begin{array}{l}\text { Musculoskeletal } \\
\text { agents }^{d}(n=13)\end{array}$ & 8.3 & 14.8 & $77.1 \%$ & 0.0109 & 0.0168 & $54.4 \%$ & 769.0 & 881.8 & $14.7 \%$ & $7.8 \%$ & $-21.6 \%$ \\
\hline $\begin{array}{l}\text { Gastrointestinal } \\
\text { agents }^{\mathrm{e}}(\mathrm{n}=14)\end{array}$ & 17.3 & 23.1 & $33.2 \%$ & 0.0123 & 0.0101 & $-17.8 \%$ & $1,404.0$ & $2,274.9$ & $62.0 \%$ & $7.9 \%$ & $3.7 \%$ \\
\hline Other classes ${ }^{\dagger}(n=302)$ & 16.4 & 21.2 & $29.2 \%$ & 0.4050 & 0.3976 & $-1.8 \%$ & 40.5 & 53.3 & $31.6 \%$ & $6.8 \%$ & $-82.9 \%$ \\
\hline $\begin{array}{l}\text { Antineoplastic agentsg } \\
(\mathrm{n}=119)\end{array}$ & 95.5 & 89.0 & $-6.7 \%$ & 0.0911 & 0.0613 & $-32.7 \%$ & $1,047.9$ & $1,451.5$ & $38.5 \%$ & $1.6 \%$ & $70.8 \%$ \\
\hline $\begin{array}{l}\text { Blood factors and } \\
\text { hemostatic modifiers } \\
(n=59)\end{array}$ & 43.5 & 35.0 & $-19.5 \%$ & 0.1525 & 0.0839 & $-45.0 \%$ & 285.2 & 417.2 & $46.3 \%$ & $-5.4 \%$ & $178.3 \%$ \\
\hline
\end{tabular}

Notes: Estimates of spending were adjusted for inflation using the Consumer Price Index..$^{13}$ Drug classes are ordered by descending changes in spending per beneficiary-year. Numbers may not sum up to totals due to rounding. All calculations were conducted from unrounded values.

aOphthalmic preparations include products with USC level 2 code 61000 and off-label intravitreal bevacizumab. We determined the intravitreal use of bevacizumab when HCPCS code $J 9035$ (bevacizumab injection) and CPT code 67028 (under vitreous procedures on the posterior segment of the eye) were concomitantly billed under the same claim. ${ }^{12}$ Our study sample included 597 HCPCS codes. However, given the split between off-label ophthalmic bevacizumab $(J 9035+67028)$ and oncologic bevacizumab (J9035), the therapeutic class sample included 598 codes.

${ }^{b}$ Antiarthritic and immunologic agents include products with USC level 2 codes 09000 and 86000.

cHospital solutions include products with USC level 2 code 53000.

dMusculoskeletal agents include products with USC level 2 code 59000.

${ }^{e}$ Gastrointestinal agents include products with USC level 2 code 23000.

'Other classes include all other USC level 2 codes.

${ }^{9}$ Antineplastic agents include products with USC level 2 codes 30000 and 35000.

${ }^{\text {hB } B l o o d}$ factor and hemostatic modifiers include products with USC level 2 codes 11000 and 48000.

CPT $=$ Current Procedural Terminology; HCPCS = Healthcare Common Procedure Coding System; USC = Uniform System of Classification .

in Supplementary Methods, available in online article). Cost per claim was calculated by dividing pharmaceutical spending by the number of claims.

Estimates of spending and utilization were expressed per beneficiary-year to account for the shorter observation period for beneficiaries with partial enrollment or who died, as well as to account for changes in Medicare enrollment over time. Estimates of spending were adjusted for inflation using the Consumer Price Index and are expressed in 2016 US dollars. ${ }^{13}$ 


\section{FIGURE 1 Overall Trends in Pharmaceutical Spending, Utilization, and Claim Cost in Medicare Part B, 2008-2016}

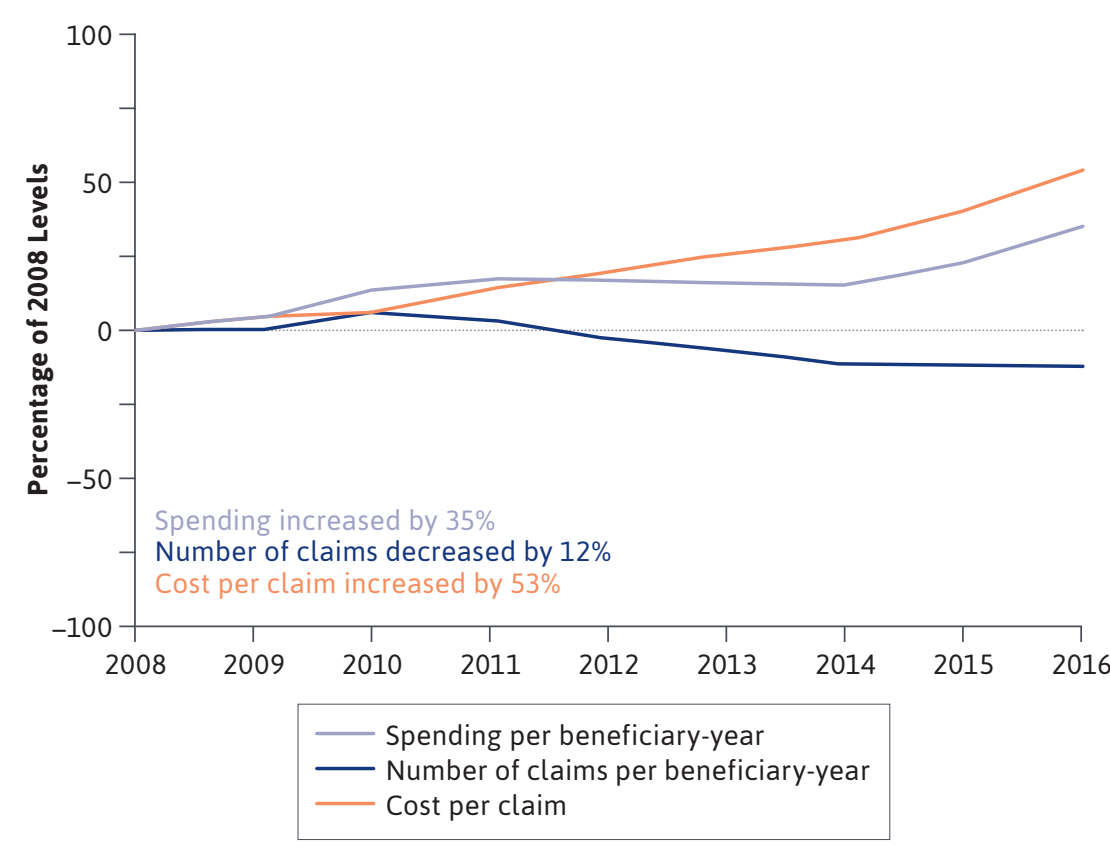

Note: Estimates of spending and cost per claim were adjusted for inflation using the Consumer Price Index ${ }^{13}$ and are expressed in 2016 US dollars.

\section{ANALYSES}

We calculated estimates of pharmaceutical spending, utilization, and cost per claim each calendar year in 20082016. For each outcome, we calculated relative changes in 2008-2016. We repeated analyses stratifying by drug type (specialty or nonspecialty) and by therapeutic class.

We further estimated the relative contribution of each subgroup toward the overall 2008-2016 change in spending and utilization. Additionally, we calculated the relative contribution of each drug type and therapeutic class toward total Medicare Part B spending and utilization each year in 2008-2016. Finally, for each therapeutic class, we calculated the relative 2008-2016 changes in spending, utilization, and cost per claim for the top 5 drugs with the largest spending in 2016. These product-level results allow us to discern what factors drive aggregated trends within the category for each therapeutic class.

\section{SENSITIVITY ANALYSES}

We repeated our analyses stratified by drug type, changing our specialty code definition. In these analyses, all HCPCS codes that included at least 1 NDC number for a specialty medication were classified as specialty and the rest as nonspecialty. All analyses were conducted at the HCPCS code level. This study was approved as exempt by the University of Pittsburgh Institutional Review Board because deidentified data was used. We conducted all analyses using statistical software SAS version 9.4 (SAS Institute).

\section{Results}

\section{CHANGES IN OVERALL PHARMACEUTICAL SPENDING, UTILIZATION, AND COST PER CLAIM}

Pharmaceutical spending per beneficiary-year in Medicare Part B increased from $\$ 213$ in 2008 to $\$ 287$ in 2016, representing a 34\% increase over this 9 -year study period (Table 1 and Figure 1). This increase was driven by a $53 \%$ increase in the cost per claim, which rose from $\$ 272$ in 2008 to $\$ 416$ in 2016. Over the study period, utilization decreased by $12 \%$, from 0.78 claims per beneficiary-year in 2008 to 0.69 in 2016.

\section{CHANGES IN PHARMACEUTICAL SPENDING, UTILIZATION, AND COST PER CLAIM BY DRUG TYPE}

Spending per beneficiary-year on specialty drugs increased by $56 \%$, from \$161 in 2008 to \$251 in 2016 (Table 1 and Figure 2). This increase was due to a $48 \%$ increase in the cost per claim of specialty drugs, which rose from $\$ 1,007$ in 2008 to $\$ 1,487$ in 2016, and a $6 \%$ increase in utilization, from 0.16 claims per beneficiary-year in 2008 to 0.17 in 2016.

Spending per beneficiary-year on nonspecialty drugs decreased by $32 \%$, from $\$ 52$ in 2008 to $\$ 36$ in 2016 (Table 1 and Figure 3). This was driven by a $17 \%$ reduction in utilization, which decreased from 0.63 claims per beneficiary-year in 2008 to 0.52 in 2016 , and a $18 \%$ reduction in the cost per claim, which decreased from $\$ 84$ in 2008 to $\$ 68$ in 2016.

The relative contribution of specialty drugs toward overall pharmaceutical spending in Medicare Part B increased from $75 \%$ in 2008 to 88\% in 2016 (Supplementary Figure 1, available in online article), while the contribution of nonspecialty drugs decreased from $25 \%$ to $12 \%$. Similarly, the relative contribution of specialty 


\section{FIGURE 2 Trends in Medicare Part B Pharmaceutical Spending, Utilization, and Claim Cost for Specialty Drugs, 2008-2016}

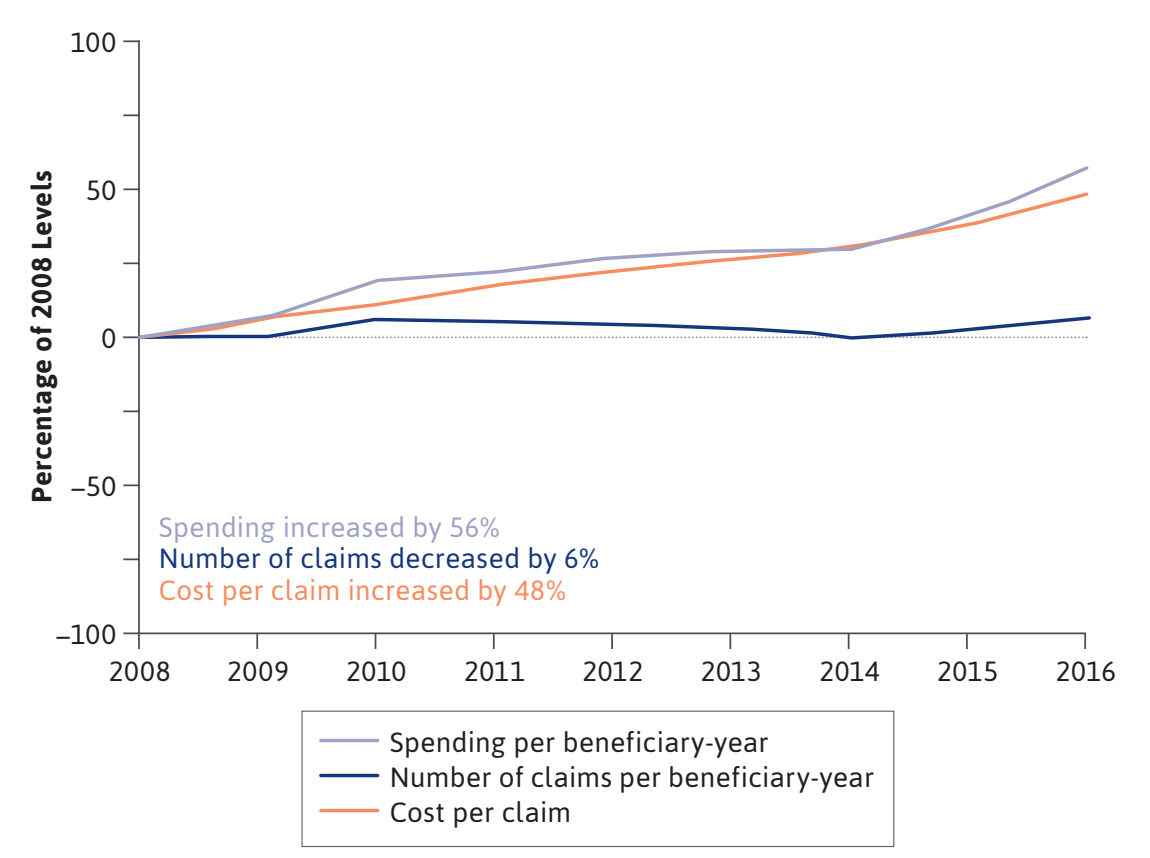

Note: Estimates of spending and cost per claim were adjusted for inflation using the Consumer Price Index ${ }^{13}$ and are expressed in 2016 US dollars.

drugs toward overall Medicare Part B utilization increased from $20 \%$ in 2008 to 25\% in 2016 (Supplementary Figure 2, available in online article), while the contribution of nonspecialty drugs decreased from $80 \%$ to $75 \%$.

\section{CHANGES IN PHARMACEUTICAL SPENDING, UTILIZATION, AND COST PER CLAIM BY THERAPEUTIC CLASS}

Over the study period (2008-2016), spending on ophthalmic preparations increased by $281 \%$, due to a $238 \%$ increase in utilization and a $13 \%$ increase in the cost per claim (Table 1, Supplementary Figure 3, and Supplementary Figure 4). This was mostly driven by the uptake of 2 highcost specialty drugs: ranibizumab and aflibercept (Supplementary Table 1). Utilization of off-label intravitreal bevacizumab also increased considerably; however, due to its low cost, it had a minimal impact on the overall spending increase within the ophthalmic preparations' category.

Spending on antiarthritic and immunologic agents increased by $159 \%$, due to a $117 \%$ increase in the cost per claim and a $19 \%$ utilization increase (Supplementary Figure 5). This was particularly driven by a large increase in price and utilization of abatacept, a large increase in price of natalizumab, and the adoption of new therapies approved throughout the study period (intra-articular hyaluronic acid and intravenous golimumab).

Spending on hospital solutions increased by $117 \%$, despite a $55 \%$ decrease in utilization, due to a $377 \%$ increase in the cost per claim (Supplementary Figure 6). This was mainly driven by changes in the drug mix, with a large decrease in utilization of less expensive hospital solutions but an increased use of high-cost therapies, such as immunoglobulins and anti-inhibitor coagulant complex.

Spending on musculoskeletal agents increased by $77 \%$, due to a $54 \%$ utilization increase and a $15 \%$ increase in the cost per claim (Supplementary Figure 7). This was primarily driven by the uptake of denosumab. Spending on gastrointestinal agents increased by $33 \%$, despite an $18 \%$ decrease in utilization, due to a $62 \%$ increase in the cost per claim (Supplementary Figure 8). This was mostly driven by an increase in price of infliximab and octreotide depot and the adoption and subsequent price increase of certolizumab.

Changes in spending, utilization, and cost per claim for all other classes are shown in Supplementary Figure 9, Supplementary Figure 10, and Supplementary Figure 11, as well as in Table 1 and Supplementary Figure 3 . The relative contribution of each therapeutic class toward total Medicare Part B spending and utilization in 2008-2016 can be found in Supplementary Figure 12 and Supplementary Figure 13, respectively (all supplementary materials are available in the online article).

\section{RESULTS OF SENSITIVITY ANALYSES}

When we modified the specialty code definition to include all HCPCS codes that included at least 1 NDC number for a specialty medication, we obtained similar results. Results of sensitivity analyses can be found in Supplementary Table 2 (available in online article).

\section{Discussion}

To our knowledge, this study is the first to quantify how changes in drug 


\section{FIGURE 3 Trends in Medicare Part B Pharmaceutical Spending, Utilization, and Claim Cost for Nonspecialty Drugs, 2008-2016}

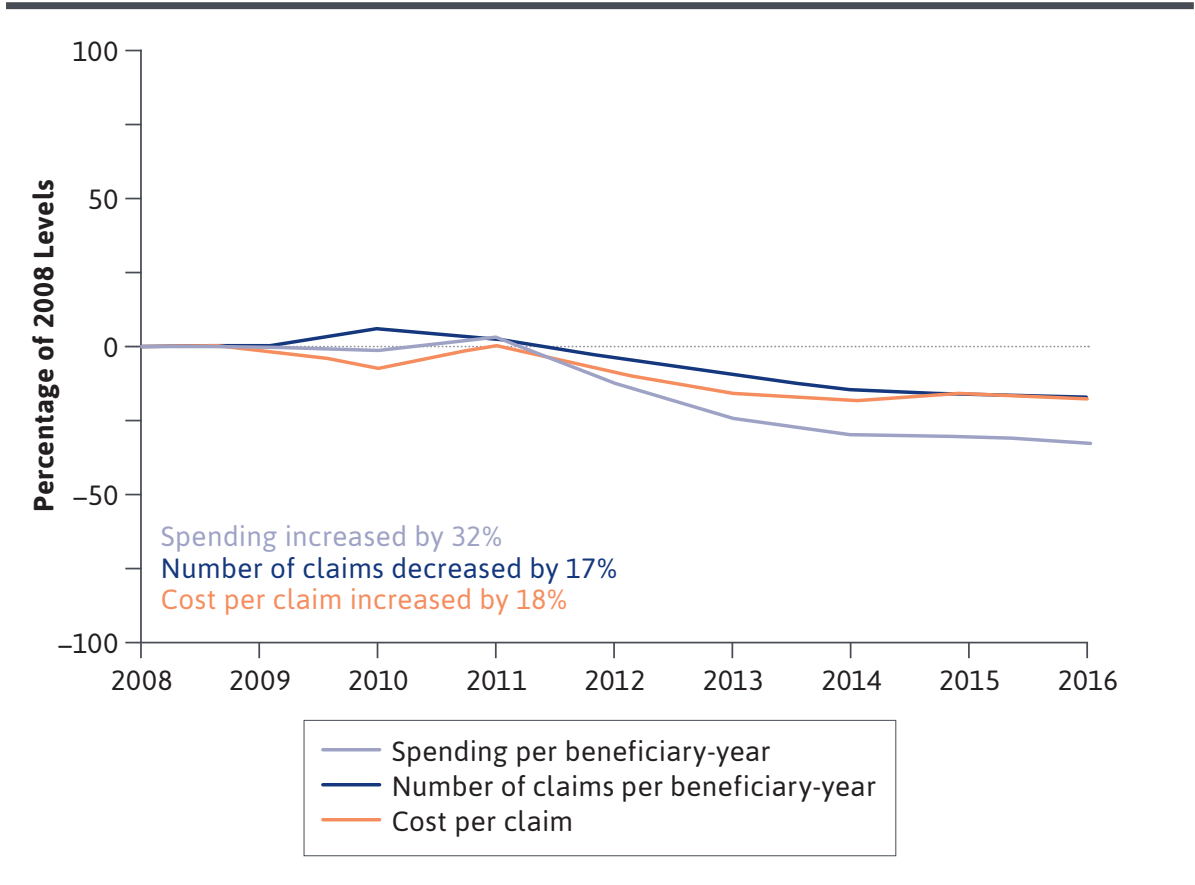

Note: Estimates of spending and cost per claim were adjusted for inflation using the Consumer Price Index ${ }^{13}$ and are expressed in 2016 US dollars.

utilization and cost per claim impact Medicare Part B pharmaceutical spending. Our study yielded 4 main findings. First, pharmaceutical spending in Medicare Part B increased by $34 \%$ over the study period, increasing at an average annual rate of $3.8 \%$ above inflation. Second, increases in Medicare Part B pharmaceutical spending were driven by increases in the cost per claim, while utilization decreased by $12 \%$. Third, despite specialty drugs representing a relatively small proportion of claims in 2016 (25\%), they accounted for the majority of the spending (88\%).

Last, we found wide variability across therapeutic classes in terms of spending and utilization trends over time.
A previous report by the Medicare Payment Advisory Commission (MedPAC) evaluated trends in drug utilization and spending in Medicare Part B from 2009-2016, finding that utilization decreased by $0.5 \%$ every year and spending increased by $6.4 \%$, driven by price growth. ${ }^{14}$ While we found similar general trends, differences in estimates are likely explained by the fact that this MedPAC report did not adjust for inflation, only included Medicare beneficiaries that used Part B drugs, and excluded blood products from analyses.

Also consistent with our findings, a report by the Government Accountability Office found that Medicare Part B pharmaceutical spending growth between 2006 and 2013 was mainly driven by new drugs, mostly specialty medications. ${ }^{6}$ In contrast, the Pharmaceutical Research and Manufacturers of America found that recent increases in Medicare Part B pharmaceutical spending were mostly driven by increased utilization measured as total number of units administered..$^{15}$ This difference may be explained by the utilization measure used-trends in the number of HCPCS code units administered-which can vary largely depending on shifts in drug mix and the unit definition of each HCPCS code.

The overall decrease in the number of claims observed for Part B drugs in 2008-2016 may be explained by a series of factors. These factors include an increased patient preference and use of oral and self-administered drugs (not generally covered by Part B), ${ }^{16,17}$ a shift in utilization toward newer drugs with less frequent dosing regimens, ${ }^{1}$ and the gradual bundling of some formerly separately payable drugs into episode-based payments, ${ }^{18}$ in particular, drugs used for the treatment of end-stage renal disease bundled into the prospective payment rate for dialysis..$^{19}$

Our study shows that overall increases in Medicare Part B pharmaceutical spending were driven by increases in the cost per claim, specifically of specialty medications. In turn, increases in the overall cost per claim are a product of changes in the drug mix, including the shift to newer, more expensive drugs, and rising drug prices. Increases in the cost per claim were also the primary driver of spending growth for most therapeutic classes with the major exception of ophthalmic preparations.

Spending on ophthalmic preparations increased substantially in 2008-2016, accounting for the majority of the overall growth in Medicare Part B pharmaceutical spending. This was primarily driven by the uptake of 2 antivascular endothelial growth 
factor therapies approved for the treatment of age-related macular degeneration, ranibizumab (launched in 2006) and aflibercept (launched in 2011). Both ranibizumab and aflibercept came into the market at very high prices,$^{12}$ and their Part B reimbursement rates have only decreased slightly over the study period. Of note, the widespread offlabel use of intravitreal bevacizumab, available at a fraction of the cost,,$^{12}$ greatly mitigated the potential for an even greater spending increase in this category.

Specialty drugs are often newer, high-cost drugs used to treat complex conditions such as cancer or rheumatoid arthritis..$^{20}$ Certain characteristics of specialty drugs make them more likely to be administered by a physician and, thus, paid for by Medicare Part B. For instance, specialty drugs are usually injected or infused, their administration requires close monitoring and individualized dosing, and they have unique handling and storage requirements due to their sensitivity to physical conditions such as light, heat, or movement. ${ }^{6}$ In fact, several reports by the Government Accountability Office demonstrated that most of newly approved specialty drugs are primarily covered under Medicare Part B as opposed to Part D. ${ }^{6,21}$ Because the majority of drugs projected to gain FDA approval in the next few years are injectable specialty drugs, ${ }^{1}$ Medicare Part B pharmaceutical spending will likely continue to increase.

Despite this, the increasing number of new biosimilar approvals, which are typically marketed at a fraction of the price of originator biologics, hold promise to lower pharmaceutical spending on Part B drugs. ${ }^{14}$ However, extensive patent litigation and settlements between manufacturers have blocked the launch of most biosimilars. Moving forward, it will be important to develop policies to protect biosimilar manufacturers and expedite the entry of biosimilars into the market.

The evidence of rising costs per claim is concerning because this can pose a severe financial hardship for beneficiaries, who are responsible for a $20 \%$ coinsurance. This is particularly true for those with modest incomes or with significant medical needs. Furthermore, unlike in Part D, out-of-pocket spending on Part B drugs has no catastrophic threshold for Medicare beneficiaries without a supplemental coverage. Out-of-pocket spending in Part B also does not count towards the catastrophic threshold in Part D, adding a significant burden to those beneficiaries that require provider-administered drugs.

Several measures have been implemented or proposed to lower drug spending for Medicare Part B and its beneficiaries. Between 1995 and 2010, Medicare used reference pricing policies, such as the least costly alternative and functional equivalence, under which a group of drugs with similar health effects were paid based on the least costly product in the group. ${ }^{22}$ These strategies linked drug reimbursement to comparative-effectiveness evidence, improving the value of care provided. ${ }^{22}$ Reinstating such policies could lead to large savings for the Medicare Part B program and its beneficiaries, particularly in certain therapeutic classes such as antiarthritics and ophthalmic preparations. ${ }^{23-25}$

Recently, MedPAC recommended that Medicare Part B develop the Drug Value Program, a voluntary alternative to the current reimbursement system that draws on market forces. ${ }^{14}$ Under this program, Medicare would obtain lower prices for Part B drugs by allowing private vendors to use pharmacy management tools (such as formulary design, step therapy, and prior authorization) to negotiate prices with manufacturers and by realigning provider incentives through shared savings opportunities..$^{14}$ MedPAC also advanced a proposal to establish common billing codes for reference biologics and their biosimilars, which would spur price competition among these Part B drugs. ${ }^{3}$

During the Trump administration, Congress proposed a series of measures aiming to control Medicare drug spending and lower beneficiaries' out-of-pocket drug costs. ${ }^{26}$ These proposals included changes to the Medicare Part B drug reimbursement system, such as establishing a price ceiling based on an international reference pricing system, developing a competitive acquisition program for Part B drugs, or capping growth of Medicare Part B drug reimbursement rates to the rate of inflation. ${ }^{26}$

Other proposals included realigning incentives for feefor-service Medicare Part B providers by substituting the current percentage-based provider add-on payment with a fixed payment, or modifying the Medicare Part B benefit design, including an out-of-pocket spending limit. ${ }^{26}$

These measures would contribute to lower drug prices of Part B drugs, constraining Medicare Part B pharmaceutical spending and ensuring beneficiaries' affordability and access to treatment.

\section{LIMITATIONS}

Our study is subject to several limitations. First, these analyses were restricted to a $5 \%$ random sample of fee-for-service Medicare beneficiaries. Second, our study includes all separately payable Part B-covered drugs in 2008-2016 and not those bundled under the Outpatient Prospective Payment System. Drugs that became bundled throughout the study period were included in the analyses only while they were separately payable. Finally, this study did not separately evaluate patient out-of-pocket spending and Medicare program payments but rather grouped them together. 


\section{Conclusions}

Medicare Part B pharmaceutical spending grew considerably in recent years, despite decreased utilization, driven by increases in the cost per claim. This was a product of rising drug prices and increased utilization of more expensive specialty drugs. These findings support the development of policies aiming to spur competition and control price growth of provider-administered drugs.

\section{DISCLOSURES}

The authors acknowledge funding from the Myers Family Foundation. Hernandez was funded by the National Heart, Lung and Blood Institute (grant number K01HL142847). Shrank is an employee of Humana. Good is an employee of the UPMC Health Plan Insurance Services Division. There are no other potential conflicts of interest to disclose.

\section{REFERENCES}

1. Magellan Rx Management.

Medical pharmacy trend report. 2018 ninth edition. 2018. Accessed February 11, 2020. https://www1. magellanrx.com/publications/ medical-pharmacy-trend-report/

2. Medicare Payment Advisory Commission. Part B drugs payment systems. Revised October 2017. Accessed February 20, 2020. http:// www.medpac.gov/docs/default-source/ payment-basics/medpac_payment_ basics 17 partb final.pdf?sfvrsn=0

3. Medicare Payment Advisory Commission. Payment policy for prescription drugs under Medicare Part B and Part D. April 30, 2019. Accessed April 12, 2021. http:// medpac.gov/docs/default-source/ congressional-testimony/04 $30 \quad 2019$ medpac drug testimony for eandc. pdf?sfvrsn $=0$
4. Medicare Payment Advisory Commission. Section 10: Prescription drugs. In: A data book: health care spending and the Medicare program. June 2017. Accessed March 1, 2020. http://www. medpac.gov/docs/default-source/databook/jun17 databooksec10 sec.pdf

5. Sheingold S, Marchetti-Bowick E, Nguyen N, Yabroff KR. Medicare Part B drugs: pricing and incentives. ASPE Issue Brief. March 8, 2016. Accessed January 20, 2020. https://aspe.hhs.gov/system/files/ pdf/187581/PartB

Drug.pdf

6. Government Accountability Office. Medicare Part B: expenditures for new drugs concentrated among a few drugs, and most were costly for beneficiaries. October 2015. Accessed March 1, 2020. https://www.gao.gov/assets/680/ 673304.pdf

7. Centers for Medicare \& Medicaid Services. Medicare Part B drug average sales price. 2020. Updated February 21, 2021. Accessed April 1, 2021. https:// www.cms.gov/Medicare/MedicareFee-for-Service-Part-B-Drugs/ McrPartBDrugAvgSalesPrice

8. CVS Specialty. CVS specialty pharmacy distribution drug list. April 2021. Accessed April 1, 2021. https://www.cvsspecialty. com/education-center/downloads/ SpecialtyDrugs.pdf

9. Hernandez I, Good CB, Cutler DM, Gellad WF, Parekh N, Shrank WH. The contribution of new product entry versus existing product inflation in the rising costs of drugs. Health Aff (Millwood). 2019;38(1):76-83.

10. IQVIA. The Uniform System of Classification (USC). April 2018. Accessed March 28, 2020. https:// www.iqvia.com/-/media/iqvia/pdfs/ institute-reports/the-uniform-system-ofclassification.pdf

11. First Databank. Drug pricing policy. Accessed March 26, 2020. https://www. fdbhealth.com/drug-pricing-policy
12. Berkowitz ST, Sternberg P Jr, Feng X, Chen Q, Patel S. Analysis of anti-vascular endothelial growth factor injection claims data in US Medicare Part B beneficiaries from 2012 to 2015. JAMA Ophthalmol. 2019;137(8):921-28.

13. Bureau of Labor Statistics. Databases, tables \& calculators by subject: Consumer Price Index. Accessed January 15, 2020. https://www.bls.gov/data/

14. Medicare Payment Advisory Commission. Chapter 3: Medicare payment strategies to improve price competition and value for Part B drugs. In: Report to the Congress: Medicare and the Health Care Delivery System. June 2019. Accessed March 1, 2020. http:// www.medpac.gov/docs/default-source/ reports/jun19_ch3_medpac_reporttocongress_sec.pdf?sfvrsn $=0$

15. The Moran Company. Trends in weighted average sales prices for prescription drugs in Medicare Part B, 2007-2017. December 2017. Accessed January 20, 2020. http://phrma-docs. phrma.org/files/dmfile/PhRMA-ASPTrend-Report-final-02212018.pdf

16. Paolella GA, Boyd AD, Wirth SM, Cuellar S, Venepalli NK, Crawford SY. Adherence to oral anticancer medications: evolving interprofessional roles and pharmacist workforce considerations. Pharmacy (Basel). 2018;6(1):23.

17. Conti RM, Fein AJ, Bhatta SS. National trends in spending on and use of oral oncologics, first quarter 2006 through third quarter 2011. Health Aff (Millwood). 2014;33(10):1721-27.

18. Werble C. Health Policy Brief. Medicare Part B. Health Affairs. August 10, 2017. doi: 10.1377/hpb20171008.000171

19. Centers for Medicare \& Medicaid Services. End stage renal disease (ESRD) Prospective Payment System (PPS). 2020. Updated March 4, 2021. Accessed April 1, 2021. https://www.cms.gov/Medicare/ Medicare-Fee-for-Service-Payment/ ESRDpayment\#Per_Treatment_Basis

20. CVS Health. What's special about specialty? Accessed March 29, 2020. https:// cvshealth.com/thought-leadership/ whats-special-about-specialty 
21. Government Accountability Office. Medicare Part B. Medicare represented at least half of the market for 22 of the 84 most expensive drugs in 2015. December 2017. Accessed April 1, 2021. https://www. gao.gov/assets/690/689082.pdf

22. Medicare Payment Advisory Commission. Chapter 4: Value-based incentives for managing Part B drug use. In: Report to the Congress: Medicare and the Health Care Delivery System. June 2015. Accessed April 1, 2021. http://medpac.gov/docs/default-source/reports/ chapter-4-value-based-incentives-formanaging-part-b-drug-use-june-2015-report-.pdf?sfvrsn $=0$
23. Congressional Budget Office. Budget options, volume 1: Health care. December 2008. Accessed April 12, 2021. https://www.cbo.gov/system/ files/110th-congress-2007-2008/ reports/12-18-healthoptions.pdf

24. US Department of Health and Human Services, Office of Inspector General. Review of Medicare Part B avastin and lucentis treatments for age-related macular degeneration. (A-01-10-00514). September 6, 2011. Accessed April 12, 2021. https://oig.hhs.gov/oas/reports/ region10/11000514.pdf
25. US Department of Health and Human Services, Office of Inspector General. Least costly alternative policies: impact on prostate cancer drugs covered under Medicare Part B. OEI-12- 12-00210. November 2012. Accessed April 1, 2021. https://oig.hhs.gov/oei/reports/oei-1212-00210.pdf

26. Freed M, Cubanski J, Neuman T. A look at recent proposals to control drug spending by Medicare and its beneficiaries. Kaiser Family Foundation. November 26, 2019. Accessed May 23, 2020. https:// www.kff.org/report-section/a-look-atrecent-proposals-to-control-drug-spending-by-medicare-and-its-beneficiariesissue-brief/\#OtherMods 